\title{
Intraconidial Conidia in the Spray Mutant of Neurospora crassa
}

\author{
By V. G. DELVECCHIO AND G. TURIAN \\ Laboratoire de Microbiologie, Institut de Botanique Générale, \\ Université de Genève, Switzerland
}

(Accepted for publication 24 February 1968)

\begin{abstract}
SUMMAR Y
The 'spray' mutant of Neurospora crassa responded differently from the wild type when grown in conidiogenic (C) and mycelial (M) media. In both media spray produced an unpigmented non-conidiating form of growth, whereas the wild type formed pure mycelial cultures on M-medium and conidiating growth on $\mathrm{C}$ medium. Analysis of the fine structure of spray revealed that the modal width of mitochondria of $\mathrm{C}$ - and M-media grown cultures was virtually identical. Since it is known that C-cultures of wild-type $N$. crassa possess swollen mitochondria, a relationship was suggested between mitochondrial swelling and the metabolic mechanisms which govern conidial differentiation. Spray also varied from the wild type in cell-wall thickness. Intraconidial conidia were observed in the spray mutant. These internal conidia always contained normal cytoplasm, while that of the host cell consisted of degenerate components. Intra-conidial conidia might arise as a result of proliferation of the septal wall.
\end{abstract}

\section{INTRODUCTION}

The changes in fine structure accompanying the process of conidiation in Neurospora have been examined by several investigators. Weiss \& Turian (I966) reported that conidial cultures (C-cultures) of wild-type Neurospora crassa possessed mitochondria which were considerably more swollen than those of mycelial cultures (M-cultures). These morphologically distinct forms were obtained by growing wildtype $N$. crassa on C-medium, which favours conidiation, or on M-medium, which gives mycelial cultures (Turian, 1964). The study of conidiation has been extended to various morphological mutants of Neurospora. Lowry, Durkee \& Sussman (1967) described the events taking place during microconidial formation in the 'peachfluffy' mutant, and Turian, Oulevey \& Tissot (1967) and Oulevey-Matikian \& Turian (I968) observed the fine structure of the 'fluffy' and 'amyc' mutants. The present paper is concerned with the detailed structural analysis of the spray morphological mutant. Its purpose was twofold. First, since spray differed from the wild type in that it did not respond to the conidiating effect of the C-medium, and therefore C- and M-cultures were identical, an electron-microscope study was made to determine whether or not the swelling of the mitochondria was related to conidial differentiation or was merely due to the composition of the medium. Secondly, with light microscopy, this mutant was seen to possess a wide variety of sizes and shapes of conidia. Some conidia resembled those of wild-type Neurospora whereas others were more elongated. 
A large percentage of mature conidia tended to remain attached to neighbouring cells, and certain conidia were found which served as hosts to internal cells which were considered to be intraconidial conidia.

\section{METHODS}

Organisms. The spray mutant $(68 A)$ was obtained from the Fungal Genetics Stock Center, Dartmouth College, Hanover, New Hampshire, U.S.A., and was originally isolated by D. D. Perkins.

Growth conditions. Conidia were obtained by growing the organism at $25^{\circ}$ on Westergaard and Mitchell solid minimal medium which was modified with respect to potassium nitrate concentration. The altered medium (designated Ps minimal) contained $2 \times 10^{-2} \mathrm{M}$-potassium nitrate instead of the usual $\mathrm{IO}^{-2} \mathrm{M}$. Conidiation usually began on the $5^{\text {th }}$ day of incubation. Samples for electron microscopy were collected at different times.

The spray mutant was also incubated at $25^{\circ}$ in $50 \mathrm{ml}$. liquid C-medium or M-minimal medium in $150 \mathrm{ml}$. Erlenmeyer flasks. These media were similar to Westergaard \& Mitchell minimal medium except for a modification in the nitrogen source according to Turian (1964). M-medium contained $\mathrm{IO}^{-2} \mathrm{M}$-diammonium citrate; to $\mathrm{C}$-medium $10^{-2} \mathrm{M}$-dipotassium citrate $+2 \times 1 \mathrm{O}^{-2} \mathrm{M}$-potassium nitrate were added. Mycelia to be examined were removed on the 3 rd day of incubation and immediately placed in fixative.

Light microscopy. Conidia and mycelia were initially observed in the unstained state; however, the use of a cellulose stain was later found to accentuate the visibility of the cell wall. The following procedure was used. Cell material suspended in $0.2 \mathrm{M}-$ hydrochloric acid was placed on a glass slide, stained with a zinc-chlor-iodide reagent (Jensen, 1962), covered with a coverslip, and examined with an O-lux Leitz microscope.

Electron microscopy. Fixation for the preparation of thin sections was done by putting the tissue in $2 \%$-potassium permanganate for $2 \mathrm{hr}$ at $5^{\circ}$. Post-staining with a saturated solution of uranyl acetate was done, followed by dehydration through a series of graded acetone water solutions. The method of Kellenberger \& Ryter (I958) was used for embedding in Vestopal W. Blocks were sectioned with glass knives on a Porter-Blum manual ultramicrotome. Sections were mounted on parlodion-covered grids and all examinations were made with an Hitachi HS- $7 \mathrm{~S}$ electron microscope.

\section{RESULTS}

\section{Description of cultures}

The spray mutant was not stimulated to produce conidia when cultivated on liquid $\mathrm{C}$-medium; cultures on $\mathrm{C}$-medium and $\mathrm{M}$-medium were identical. In liquid cultures spray formed many unpigmented isolated colonies, presumably the result of growth of the individual conidia of the conidial inoculum. Occasionally after the 8th day of incubation some liquid cultures showed very slight conidiation in the area of the walls of the flask just above the surface of the medium. This conidiation took place in both C-cultures and M-cultures, and only at a few isolated sites along the surface of the medium due to attachment of mycelia there to the walls of the flask. The amount of conidiation was virtually negligible when compared to that of cultures grown on Ps solid medium. 
Conidiation and carotenoid production of spray were greatly enhanced on solid Ps medium, where the production of conidia usually began between the 5 th and 6 th day of incubation. On solid medium the mycelia were characterized by a more restricted growth than wild-type Neurospora. Periodicity was never displayed.

\section{Light-microscope observations}

Mycelia were considerably branched and very septate. Conidia showed a wide variety of sizes and shapes. A percentage of spray conidia resembled those found in the wild type; however, the majority were greatly elongated and sometimes showed a reluctance to separate from neighbouring cells (Pl. I, fig. I). An interconidial bridge was noted between these attached cells. Conidia were also found which possessed internal conidia (P1. I, figs. 2, 3).

\section{Electron microscopy}

Except for the cell wall the fine-structure morphology of the spray mutant was similar to that described by Shatkin \& Tatum (1959) and Weiss \& Turian (1966) for wild-type Neurospora; the cell wall of the spray mutant was, however, considerably thicker and very electron-transparent.

The major difference between the spray mutant and the wild type was in the behaviour on C- and M-media. The width of the mitochondria of spray in C- and Mmedia was identical with a modal width value of between 0.20 and $0.28 \mu$, whereas C-cultures of wild type, as reported by Weiss \& Turian (I966), had mitochondria which were more swollen than those of M-cultures.

Conidia were grouped in two types by means of electron microscopic examination: ovoid conidia which resembled those found in the wild type (Pl. 2, fig. 6); conidia which served as hosts to internal conidia (Pl. 3, figs. 7, 8). The cell wall of such intraconidial conidia was similar to that of the host cell. The internal conidia contained cytoplasm which had all the normal components, while the cytoplasm of the external cell was always composed of degenerate structures. Finally, an intercellular septum was observed which displayed an internal extension of its wall into the cytoplasm (Pl. 3, fig. 9). This extension may represent an initial stage in the development of internal conidia.

\section{DISCUSSION}

The 'spray' mutant behaved differently from wild-type Neurospora crassa in C- and M-media. This difference was not only reflected in the gross morphology but also in the fine structure. The lack of swelling of the mitochondria of spray C-medium cultures suggests that the mitochondrial size variations of wild-type $N$. crassa may be related to metabolic processes governing morphogenesis. C- and M-media grown cultures of spray had mitochondria with a modal width between 0.20 and $0.28 \mu$, a range intermediate to the value obtained by Weiss \& Turian (1966) for C-and M-cultures of wild type. It is difficult to relate mitochondrial swelling to metabolic activity; however, the data suggest a connexion between inflated mitochondria and metabolic mechanisms governing conidial differentiation.

An exceptionally thick cell wall was seen in the spray mutant. The composition of cell wall has been implicated in the determination of fungal morphology. BartnickiGarcia \& Nickerson (1962) reported fine-structure modifications in the thickness of 
the cell wall of Mucor rouxii and correlated this alteration with quantitative differences in the cell. Mahadevan \& Tatum (I965) showed alterations in cell-wall constituents in sorbose-induced and mutated colonial morphological forms of Neurospora. Finestructure cell-wall variations have been reported for other morphological mutants of Neurospora. Lowry, Durkee \&Sussman (1967) pointed out that the 'peach-fluffy' microconidial cell wall was more extensively layered than that of the wild type; OuleveyMatikian \& Turian (I968) found an extremely thick cell wall in the 'amyc'mutant. In view of these findings it is not surprising that the morphological spray mutant displayed an abnormally thick cell wall.

Intra-conidial conidia were observed in the 'spray' mutant. These internal forms had a cell wall which resembled that of the host cell in appearance. All normal cytoplasmic components were found in these internal cells, while those of host cells were always degenerate. This is reminiscent of the intra-hyphal hyphae of the 'clock' mutants described by Lowry \& Sussman (I966). Another similarity between 'clock' and 'spray' was the high incidence of moribund hyphae found. However, the 'spray' never displayed periodicity under the growth conditions described.

Kendrick \& Molnar (1965), with Ceratocystis dryocoetidis, explained the formation of intrahyphal hyphae and endoconidia as the possible result of proliferation of the septum. The median proliferation of the septum that we observed in the spray mutant of Neurospora crasa might represent an early stage in the development of intraconidial conidia.

The authors are indebted to Miss B. ten Heggeler for her technical advice. This work was supported in part by Postdoctoral Research Grant I-F 2-GM-3I, 86I-0I from the National Institute of Health, United States Public Health Service to one of the authors (V.G.D.).

\section{REFERENCES}

Bartnicki-Garcia, S. \& Nickerson, W. J. (1962). Isolation, composition, and structure of cell walls of filamentous and yeast-like forms of Mucor rouxii. Biochim. biophys. Acta 58, 102.

Jensen, W. A. (1962). Botanical Histochemistry, p. I93. San Francisco: W. H. Freeman and Co.

KELLENBERGER,E. \& RYTER, A. (I958). L'inclusion au polyester pour l'ultramicrotomie. J. Ultrastuct. Res. 2, 200.

Kendrick, W. B. \& Molnar, A. C. (1965). A new Ceratocystis and its Verticicladiella imperfect stage associated with the bark beetle Dryocoetes confusus on Abies lasiocarpa. Can. J. Bot. 43, 39.

Lowry, R. J. \& Sussman, A. S. (I966). Intra-hyphal hyphae in 'clock' mutants of Neurospora. Mycologia $\mathbf{5 8}, 54 \mathrm{I}$.

Lowry, R. J., Durkee, T. L. \& Sussman, A. S. (1967). Ultrastructural studies of microconidium formation. Neurospora Newsletter II, 9.

Mahadevan, P. R. \& Tatum, E. (1965). Relationship of the major constituents of the Neurospora crassa cell wall to wild-type and colonial morphology. J. Bact. 90, 1073.

Oulevey-Matikian, N. \& Turian, G. (1968). Contrôle métabolique et aspects ultrastructuraux de la conidiation (macro-micro conidies) de Neurospora crassa. Arch. Mikrobiol. 6o, 35.

Shatkin, A. J. \& Tatum, E. (1959). Electron microscopy of Neurospora crassa mycelia. J. biophys. biochem. Cytol. 6, 423 .

TURIAN, G. (1964). Synthetic conidiogenous media for Neurospora crassa. Nature, Lond. $202,1204$.

Turlan, G., Oulevey, N. \& Tissot, F. (1967). Preliminary studies on pigmentation and ultrastructure of microconidia of Neurospora crassa. Neurospora Newsletter II, I7.

Weiss, B. \& Turian, G. (I966). A study of conidiation in Neurospora crassa. J. gen. Microbiol. 44, 407. 
Journal of General Microbiology, Vol. 52, No. 3

Plate I
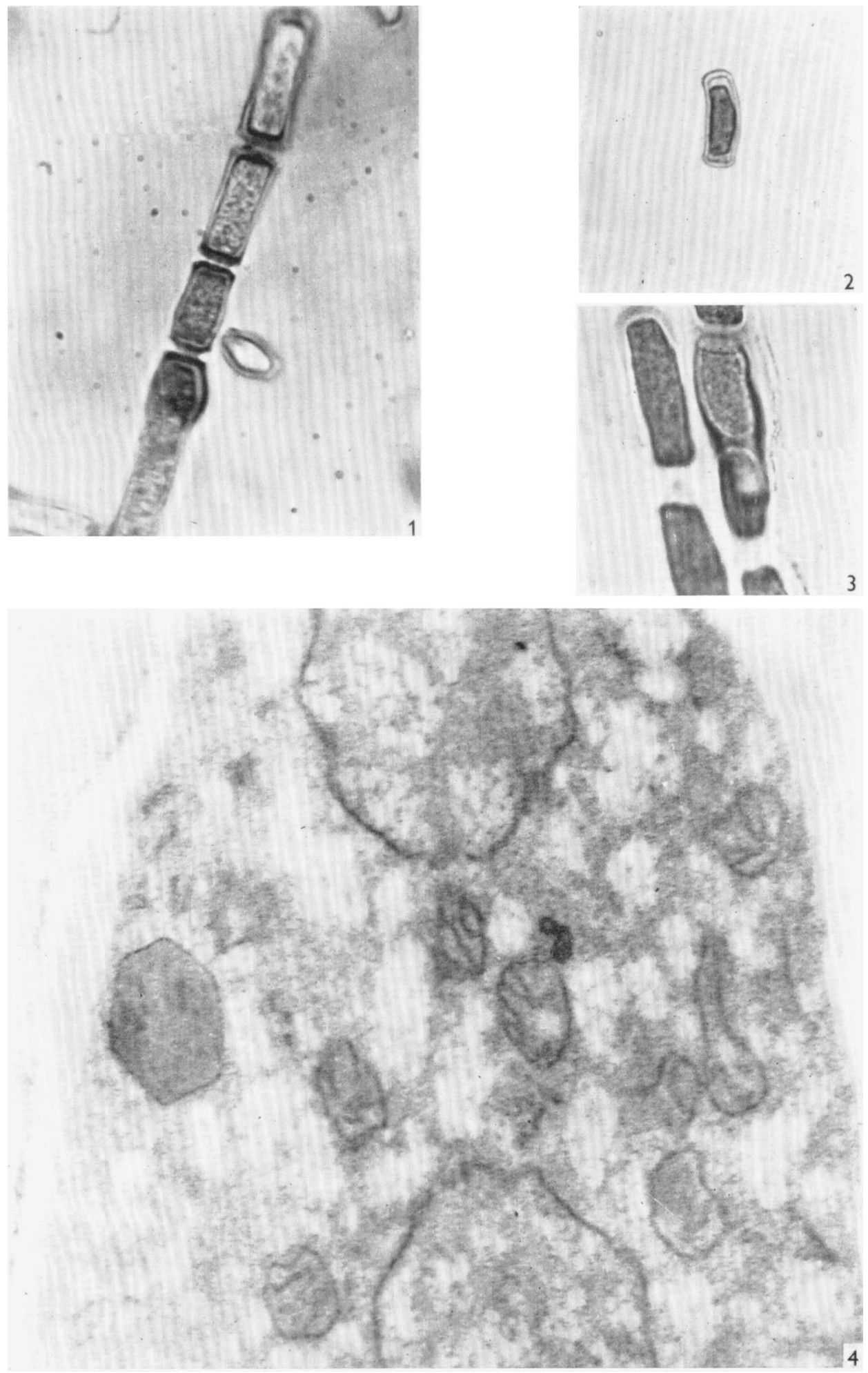
Journal of General Microbiology, Vol. 52, No. 3

Plate 2
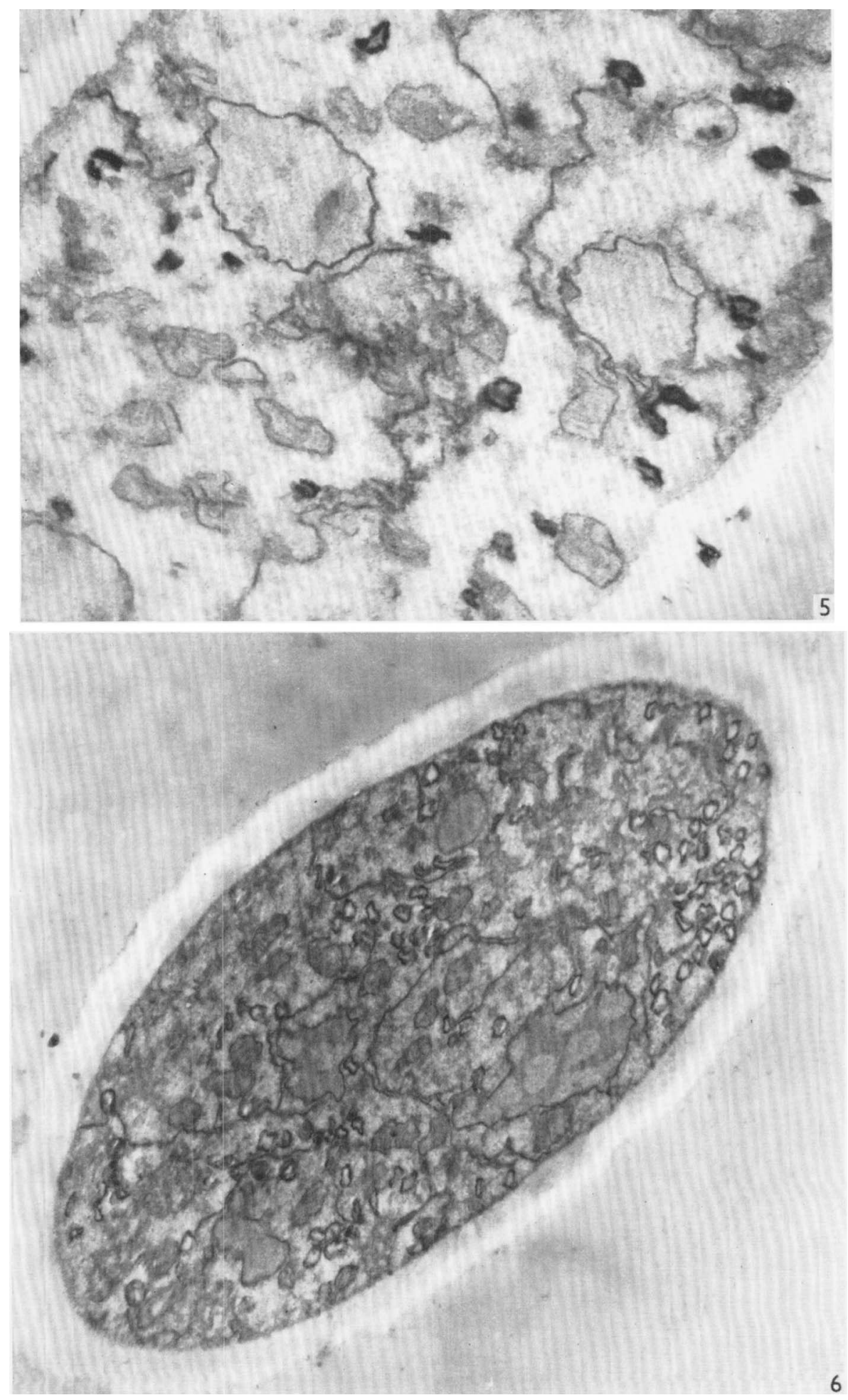

V. G. DELVECCHIO AND G. TURIAN 
Journal of General Microbiology, Vol. 52, No. 3

Plate 3

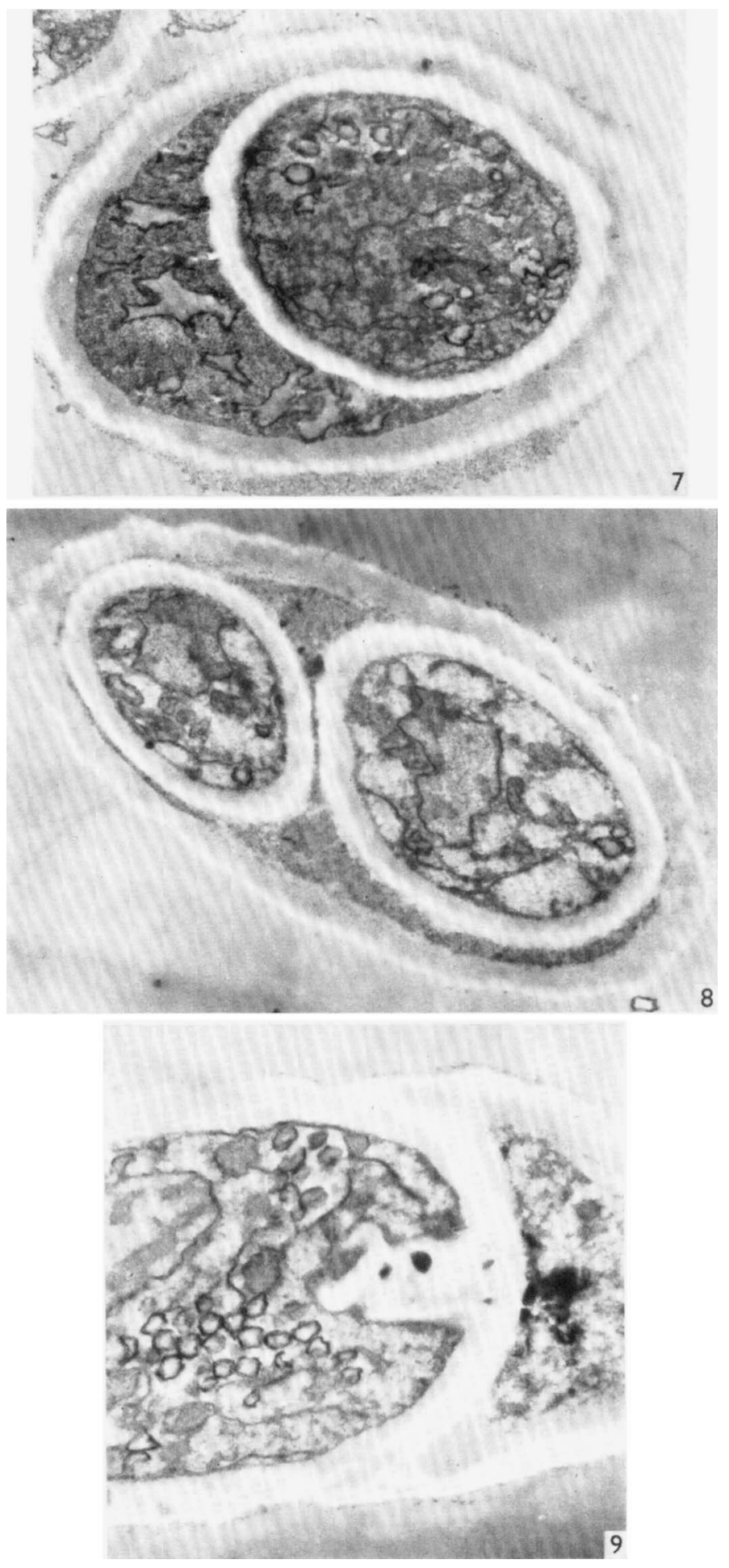

V. G. DELVECCHIO AND G. TURIAN 

EXPLANATION OF PLATES

Light micrographs of Neurospora crassa spray mutant cellular material stained with zinc-chlor-iodide reagent; figs. I-3. All electron micrographs of spray were fixed with $\mathrm{KMnO}_{4}$ and stained with uranyl acetate; figs. $4-9$.

\section{Plate I}

Fig. I. A chain of elongated conidia interconnected with bridges. Immediately to the right of the chain is an isolated conidium which resembles a normal ovoid wild-type conidium. $\times 1075$.

Fig. 2. Conidium which contains an intraconidial conidium. $\times 1075$.

Fig. 3. The most elongated conidium in this group of conidia can be seen to possess two intraconidial conidia. $\times 1075$.

Fig. 4. A section of hypha taken from a culture grown for 3 days in M-medium. The cytoplasmic components are similar to those grown in C-medium (Pl. 2, fig. 5). On the left is an hexagonal crystal presumed to be ergosterol. $\times 21,000$.

\section{Plate 2}

Fig. 5. A section through a hypha obtained from a 3-day $\mathrm{C}$-medium culture. The cell wall is thick and electron-transparent. The mitochondria have well-defined cristae with restricted matrices, and the endoplasmic reticulum is continuous with the nuclear membrane. $\times 21,000$.

Fig. 6. A section through a conidium obtained from an 8-day culture grown on Ps solid medium. The mitochondria are well defined as are the other cytoplasmic components. The characteristically thick cell wall is present. $\times 2 \mathrm{I}, 000$.

\section{Plate 3}

Fig. 7. A conidium containing an intraconidial conidium. Note the moribund cytoplasm of the host cell whereas that of the internal cell is normal. $\times 2 \mathbf{I}, 000$.

Fig. 8. A conidium with two internal conidia. Each internal cell possesses a nucleus. Again the cytoplasm of the host cell is moribund. $\times 21,000$.

Fig. 9. Section through a septum showing a median extension of the wall. $\times 24,500$. 